\title{
Death from 2,4-Dinitrophenol Poisoning: An Autopsy Case
}

Moonhee Jung ${ }^{1}$, Su Jin Lee ${ }^{1}$, Seong Ho Yoo ${ }^{2}$, Hyung-Seok Kim ${ }^{1}$

${ }^{1}$ Department of Forensic Medicine, Chonnam National University Medical School, Gwangju, Korea, ${ }^{2}$ Institute of Forensic Medicine and Department of Forensic Medicine, Seoul National University College of Medicine, Seoul, Korea

Received: July 22, 2020

Revised: August 27, 2020

Accepted: August 28, 2020

\section{Correspondence to}

Hyung-Seok Kim

Department of Forensic Medicine, Chonnam National University Medical School, 160 Baekseo-ro, Dong-gu, Gwangju 61469, Korea Tel: +82-62-220-4090

Fax: +82-62-223-4250

E-mail:veritas@jnu.ac.kr
DNP (2,4-dinitrophenol) has been commonly used as a weight loss aid; in particular, it has been used by body builders to achieve significant fat loss while maintaining muscle mass. The sale of DNP was banned due to some cases of fatal poisoning. We describe an autopsy case of a 39-year-old man who died from taking DNP to treat obesity. He was $183 \mathrm{~cm}$ tall and weighed 101 $\mathrm{kg}$ (body mass index of 31). External examination did not reveal any specific findings implicating the cause of death. Gross examination revealed that the heart weight was $450 \mathrm{~g}$, and there were no significant findings in the coronary arteries and myocardium, except for a few petechiae of the epicardium. The DNP concentration in the subject's blood was $38.28 \mathrm{mg} / \mathrm{L}$. According to references, a DNP blood concentration of $28 \mathrm{mg} / \mathrm{L}$ or higher would result in death. Therefore, the cause of death in this autopsy case was DNP toxicity.

Key Words: 2,4-Dinitrophenol; Diet drug; Intoxication; Sudden death; Autopsy

\section{Introduction}

Recently, the number of people using 2,4-dinitrophenol (DNP) for weight loss has greatly increased. DNP increases the basal metabolic rate, resulting in weight reduction. The high metabolic rate is achieved by uncoupling mitochondrial oxidative phosphorylation, which generates intracellular heat, resulting in an inability to control thermogenesis via the inhibition of ATP formation. However, DNP was banned because of serious adverse effects such as hyperthermia, tachycardia, and diaphoresis. DNP poisoning causes cataracts, liver failure, and agranulocytosis, leading to death. More than 60 cases of DNP-related death have been reported in the literature. However, there have been no reports of DNP-related deaths in Korea. In this report, we describe a rare autopsy case of a 39-year-old man who died after consumption of DNP, which he was using as a weight loss aid.

\section{Case Report}

A 39-year-old man who lived alone was prescribed drugs for the treatment of hyperlipidemia and sinusitis. He purchased DNP for weight loss on a regular basis from an online merchant. At the time of his death, his 
colleague found him lying on the floor of the bathroom.

The subject was $183 \mathrm{~cm}$ tall and weighed $101 \mathrm{~kg}$ (body mass index is 31). Livor mortis was apparent as a dark red coloration of the chest and back of the body was present. On external examination, both his palpebral conjunctivas were congested with blood. Except for slight abrasions and contusions on the forehead and both arms and legs, no specific findings indicating the cause of death were observed.

Gross examination revealed no evidence of specific brain injury. The heart weight was $450 \mathrm{~g}$, and a few petechiae were observed on the epicardium. There were no significant findings involving the coronary arteries or myocardium (Figs. 1, 2). The thickness of the left ventricle and septum was $1.5 \mathrm{~cm}$ and $1.5 \mathrm{~cm}$, respectively. The left and right lung weights were 550 $\mathrm{g}$ and $602 \mathrm{~g}$, respectively, and there was froth in the

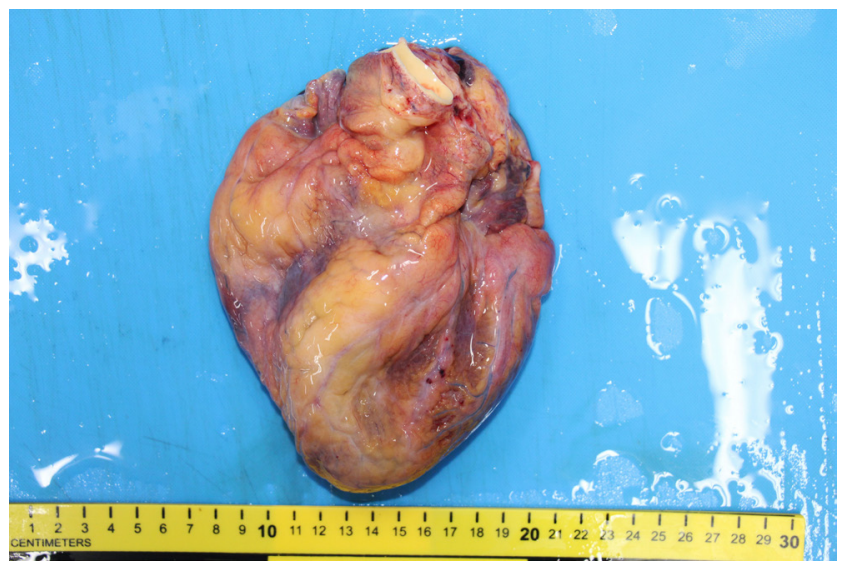

Fig. 1. The heart shows a few petechiae on epicardium.

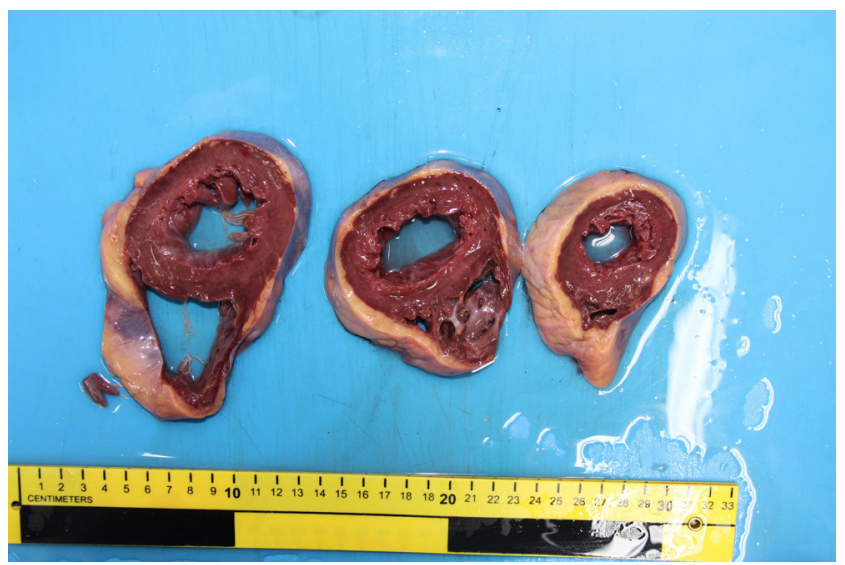

Fig. 2. The gross examination of heart reveals no significant findings implicating the cause of death. bronchus of the left lung. The liver weight was 1,812 $\mathrm{g}$, and no specific findings were evident in the liver or other organs, including the kidney, spleen, and pancreas. The gastric contents were in a liquid state.

Toxicological results revealed DNP in the patient's blood, gastric contents, and urine, and the DNP concentration of cardiac blood was $38.28 \mathrm{mg} / \mathrm{L}$. The alcohol concentration in the patient's blood was less than $0.010 \%$, and acetone and beta-hydroxybutyrate were 10 and $40 \mu \mathrm{g} / \mathrm{mL}$, respectively (Table 1 ).

The overall findings were as follows: (1) The DNP concentration of blood was $38.28 \mathrm{mg} / \mathrm{L}$; (2) The heart weight was $450 \mathrm{~g}$, indicating an enlarged heart; however, this finding was thought to be due to chronic disease; (3) There were no other abnormal findings implicating the cause of death (other diseases, fatal injury, etc.). Therefore, the cause of death in this autopsy case was DNP toxicity.

\section{Discussion}

DNP is a yellow crystalline powder that is soluble in water and has been used in the production of pesticides, dyes, wood preservatives, and explosives [1,2]. The administration of a small dose of DNP has been reported to promote fat mobilization. However, DNP is a chemical uncoupler of oxidative phosphorylation, which is one of the important metabolic pathways for obtaining ATP via the secretion of calcium ions from the mitochondria. In conclusion, DNP metabolism causes muscle contraction and hyperthermia due to increased free intracellular calcium [3,4].

In the 1930s, DNP gained great popularity as a

Table 1. DNP, acetone, and BHB concentration in patient's blood

\begin{tabular}{ll}
\hline \multicolumn{1}{c}{ Analysis marker } & Value $^{\mathrm{a})}$ \\
\hline 2,4-Dinitrophenol (DNP) & $38.28 \mathrm{mg} / \mathrm{L}$ \\
Acetone & $10 \mu \mathrm{g} / \mathrm{mL}$ \\
Beta-hydroxybutyrate (BHB) & $40 \mu \mathrm{g} / \mathrm{mL}$ \\
\hline
\end{tabular}

${ }^{a)}$ According to national forensic service, blood DNP concentration in asymptomatic state have yet not been reported, blood DNP concentration of patients who died from taking DNP was $28-48 \mathrm{mg} / \mathrm{L}$. There were detected less than $10 \mu \mathrm{g} / \mathrm{mL}$ acetone concentration and $8-31 \mu \mathrm{g} / \mathrm{mL}$ BHB concentration in normal group. Autopsy control groups were reported negative- $24 \mu \mathrm{g} / \mathrm{mL}, 19-134 \mu \mathrm{g} / \mathrm{mL}$ in acetone and $\mathrm{BHB}$ concentration, respectively. 
weight-loss supplement in the treatment of obesity. DNP consumption of $300-400 \mathrm{mg}$ daily resulted in a $36 \%-95 \%$ increase in basal metabolic rate [5]. The sale of DNP has been prohibited due to serious side effects, such as hyperthermia, tachycardia, and diaphoresis; however, it can be easily purchased from merchants via the Internet [6]. Although a great number of people have been exposed to addiction risk, there is no known specific antidote [7]. Most patients have to receive cooling treatment with ice bags and normal saline to maintain homeostasis (water, electrolytes, acid-base status, etc.) [8].

DNP poisoning causes cataracts, liver failure, and agranulocytosis, leading to death. According to references, a DNP blood concentration of $28 \mathrm{mg} / \mathrm{L}$ or higher would result in death [9]. In this case report, the DNP concentration of the subject's blood was 38.28 $\mathrm{mg} / \mathrm{L}$. There were no specific findings on external and gross examination, except for DNP blood concentration. Consequently, the cause of death in this case was DNP toxicity.

DNP drugs have been used for cosmetic purposes in the past but are now considered dangerous because of the potential to cause fatal poisoning. More than 60 cases of DNP-related death have been reported in the literature from 1919 to 2019. However, there have been no reports of DNP-related deaths in Korea until this report, which describes a rare autopsy case of DNP poisoning in Korea. We hope that this report is a good guide considering similar cases of death caused by overdose or long-term use of DNP.

The Ministry of Food and Drug Safety recommended that people do not purchase products containing DNP via the Internet according to overseas risk information, and the Korea Communications Commission and the National Tax Service were requested to block Internet sales and ban customs clearance of DNP. Dietary supplements containing DNP are not permitted to be sold in Korea but can still be purchased by individuals through overseas shopping malls. For the health and safety of the population, the management of DNP sales needs to be more stringent.

ORCID: Moonhee Jung: https://orcid.org/0000-00015382-8459; Su Jin Lee: https://orcid.org/0000-00034337-8081; Seong Ho Yoo: https://orcid.org/0000-00015294-0596; Hyung-Seok Kim: https://orcid.org/00000002-8297-9747

\section{Conflicts of Interest}

Seong Ho Yoo, contributing editor of the Korean Journal of Legal Medicine, were not involved in the editorial evaluation or decision to publish this article. All remaining authors have declared no conflicts of interest.

\section{References}

1. Siegmueller C, Narasimhaiah R. 'Fatal 2,4-dinitrophenol poisoning... coming to a hospital near you'. Emerg Med J 2010;27:639-40.

2. Grundlingh J, Dargan PI, El-Zanfaly M, et al. 2,4-dinitrophenol (DNP): a weight loss agent with significant acute toxicity and risk of death.J Med Toxicol 2011;7:205-12.

3. Yen M, Ewald MB. Toxicity of weight loss agents. J Med Toxicol 2012;8:145-52.

4. Maragos WF, Korde AS. Mitochondrial uncoupling as a potential therapeutic target in acute central nervous system injury. J Neurochem 2004;91:257-62.

5. Tewari A,Ali T, O'Donnell J, et al. Weight loss and 2,4-dinitrophenol poisoning. Br J Anaesth 2009;102:566-7.

6. Geraldo de Campos E, Fogarty M, Spinosa De Martinis B, et al. Analysis of 2,4-dinitrophenol in postmortem blood and urine by gas chromatography-mass spectrometry: method development and validation and report of three fatalities in the United States. J Forensic Sci 2020;65:183-8.

7. Holborow A, Purnell RM, Wong JF. Beware the yellow slimming pill: fatal 2,4-dinitrophenol overdose. BMJ Case Rep 2016;2016:bcr2016214689.

8. Lu YQ, Jiang JK, Huang WD. Clinical features and treatment in patients with acute 2,4-dinitrophenol poisoning. J Zhejiang Univ Sci B 2011;12:189-92.

9. Miranda EJ, McIntyre IM, Parker DR, et al. Two deaths attributed to the use of 2,4-dinitrophenol.J Anal Toxicol 2006;30:219-22. 